\title{
Design and Analysis of Cover Handle Bar Top (Injection moulding process)
}

\author{
Ingole Akshay Rambhau*, Joglekar Saurabh Ashwinkumar, Jori Prasad Rajendra, Kulkarni Nikhil Narayan \\ and B.D.Patil
}

Mechanical, Sinhgad Institute of Technology and Science, Narhe, Pune

Accepted 02 March 2016, Available online 15 March 2016, Special Issue-4 (March 2016)

\begin{abstract}
This is focused on the design and analysis of cover handle bar top with the help of injection moulding. Injection moulding process is a vast and advantageous process in the field of science and technology. There are basically three steps in the injection moulding cycle. First step is design of sprue which is tapered to increase the rate of flow. Second step is design of runner whose efficiency is pre-determined and fixed. The final step is selection of the gate which pours the flow material finally into the cavity. Selection of gate is quite a difficult task for the designer. Mould flow analysis software is used to perform the analysis of filling, wrap and best gate location. This analysis will discuss the flow of molten plastic inside the injection mould. The analysis begins with the origin of the flow channels such as barrel, nozzle, sprue, runner and gate until the cavity is completely filled. It helps to determine the part defects that might occurred during plastic injection molding process such as short shot, unequal filling, over filling, welding lines and others. From that, the optimum parameters setting are selected in order to get a quality injection molded component. This paper discuss about design and analysis of gating system..
\end{abstract}

Keywords: Injection moulding, Mould flow analysis, sprue, gate, runner, short shot, welding line

\section{Introduction}

In this project, injection moulding is used as a manufacturing process to manufacture cover handle bar top. This part finds its application in light transport and commercial vehicle. This part is design to increase the basic functional requirement of customer and ergonomics. Plastics are of two types-thermoplastic and thermosets. The thermoplastic do not undergo chemical change in their chemical composition when they are heated and thus, can be moulded all over again. Thermosets melt and take shape once (Kapila, et $a l, 2015)$.The part is made up of polypropylene copolymer which is thermoplastic in nature. The density and tensile strength of material is $950 \mathrm{Kg} / \mathrm{m}^{\wedge} 3$ and 40 $\mathrm{MPa}$ respectively. Melting point is $200^{\circ} \mathrm{C}$. Horizontal type of injection moulding machine is used to manufacture Cover handle bar top. Injection moulding machines are known as presses. They are rated in terms of Tonnes; it represents how much amount of clamping force that the machine can generate. Capacity of injection moulding machine that is specifically required to mould this component is 180 Tonnes. Mould flow analysis software is used to perform filling, wrap and best gate location (Rao and Ramni, 2013).

1.1 Injection process

*Corresponding author: Ingole Akshay Rambhau
In process of injection moulding, from hopper granular plastic is fed by gravity into heated barrel. By a screw plunger the granules are moved forward, the plastic is forced into a heated chamber where it melts completely. When the plunger moves forward, through a nozzle the melted plastic is forced in, letting it to enter the cavity through a gate and runner system. As the plastic solidifies the mold remains cold almost as it is completely filled (Galantucci and Spina, 2003).

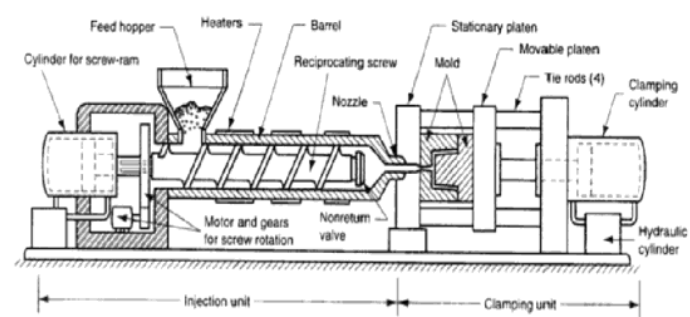

Fig. 1 Injection Moulding Machine

\subsection{Cycle of injection moulding}

The injection moulding cycle is the sequence of events that occur during the injection mould of plastic part. With the mould closing the cycle begins, followed by injecting the polymer into the cavity. A holding 
pressure is maintained when the cavity is filled, to compensate for material shrinkage operation. The screw turns, feeding the next shot to the front screw- in the next step of the cycle. The mould open and the part is ejected, once the part is cooled (Galantucci and Spina, 2003).

\section{Problem statement}

A parameter setting and feeding system such as gate, runner and sprue inside the plastic injection mould are located by mould makers using trial and error method. Simulation software is the new technology that can examine the behavior of plastic flow inside the cavity mould. This software decides the better method to select the best design for feeding system like runner, sprue, gate and other process parameter. The size of gate, runner and sprue is important thing to consider for producing good quality plastic product. The Plastic adviser Software is one of software used to ensure the best choice location of feeding system and size of gate, runner and sprue. The objective is to optimize the fill process of a mould and the integrity of the moulded part. The data provided during the analysis helps the engineer to select the optimum location for gate, sprue and runner. Temperature variations and all the suitable parameter are clearly defined in the simulation. The end result is accurate, economical and reliable plastic parts.

\section{Objectives}

- Understanding the component design.

- Identifying the critical locations in the component such as gate location, air traps, parting line.

- Suggest the modifications in the component without affecting its functionality to simplify the mould with smooth flow of molten plastic.

- Use of Mould flow analysis to perform the analysis of filling, wrap and best gate location.

- To determine the part defects such as short shot, unequal filling, over filling, welding lines and others.

- To reduce injection moulding cycle time.

\section{Scope}

- Design and detailing for manufacturing the mould.

- Reducing the uncertainty in selecting process parameters by using Mould Flow Analysis instead of trial and error.

\section{Methodology}

- 2D Drawing from customer

- 3D Model Preparation using CATIA Software

- Feasibility Study (Tolerances)

- $\quad$ Technical Study (SOR), checking gauges \& cooling fixtures

- Basic Tool Design
- Gate position

$\circ \quad$ Ejector pin position

- Parting line

- Mould Flow Analysis

- Inspection of component

- Rectification and improvement

- Approval

\section{Gating system design}

STEP -1

i. Surface Area, Volume and type of material is calculated.

ii. Velocity of flow is decided by the designer which is fixed for every material.

iii. For example gate velocity $=5 \mathrm{~m} / \mathrm{s}$ to $30 \mathrm{~m} / \mathrm{s}$

iv. (Minimum for house hold product and max for ABS material)

v. No. of cavities are selected either it must be single cavity or multi cavity according to the demand of customer.

vi. Gate is selected by the designer.

Table 1 Material types

\begin{tabular}{|c|c|c|}
\hline $\begin{array}{c}\text { Sr. } \\
\text { No. }\end{array}$ & Material types & $\begin{array}{c}\text { Material } \\
\text { constants }\end{array}$ \\
\hline 1 & $\begin{array}{c}\text { Polythene, polystyrene: } \\
\text { Density=1.05 gm/cm^3 }\end{array}$ & $\mathrm{n}=0.6$ \\
\hline 2 & $\begin{array}{c}\text { Polyacetal, polycarbonate: } \\
\text { Density=1.21 gm/cm³ }\end{array}$ & $\mathrm{n}=0.7$ \\
\hline 3 & $\begin{array}{c}\text { Cellulose acetate, polymethyl } \\
\text { methaacrylate, nylone: } \\
\text { Density }=0.941 \text { gm/cm³ }\end{array}$ & $\mathrm{n}=0.8$ \\
\hline 4 & PVC: Density $=1.38 \mathrm{gm} / \mathrm{cm}^{\wedge} 3$ & $\mathrm{n}=0.9$ \\
\hline
\end{tabular}

\section{STEP-2}

Gate area is calculated by:

Gate area $=\frac{\text { Total volume of cavity }}{\text { Gate velocity }}$

Width of gate $=\frac{n * \sqrt{A}}{30}$

Gate thickness is calculated by the relation:

Gatethickness $=\frac{\text { Gate area }}{\text { Gate width }}$

Gate thickness determines the type of gate used for a particular type of cavity. 
Table 2 Selection of gate

\begin{tabular}{|c|c|c|}
\hline Sr. No. & Gate thickness in $\mathrm{mm}$ & Type of gate use \\
\hline 1 & 0.1 to 0.59 & Film gate/flash gate \\
\hline 2 & 0.6 to 0.99 & Fan \\
\hline 3 & 1.0 to 5.0 & Side/edge gate \\
\hline 4 & 0.1 to 0.89 & $\begin{array}{c}\text { Ring } \\
\text { gate/Trapezoidal }\end{array}$ \\
\hline 5 & 1.0 to1.59 & Submarine gate \\
\hline 6 & 1.6 to 5.0 & Ring gate \\
\hline
\end{tabular}

STEP-3

In this step runner is selected according to the performance efficiency. It is being observed by designer that

Table 3 Selection of runner

\begin{tabular}{|c|c|c|}
\hline Sr. No. & Type & $\begin{array}{c}\text { Priority (acc.to } \\
\text { efficiency) }\end{array}$ \\
\hline 1 & Trapezoidal (D=W) & 2 \\
\hline 2 & Round (D) & 3 \\
\hline 3 & $\begin{array}{c}\text { Modified Trapezoidal } \\
\text { (R=D/2) }\end{array}$ & 1 \\
\hline 4 & Hexagonal & 4 \\
\hline
\end{tabular}

Runner diameter is given by

$D=\frac{\sqrt{\text { Weightof moulding }}}{3.7} * \sqrt[4]{\text { Lengthof runner }}$

[Note: If length of runner is less than $125 \mathrm{~mm}$ then diameter of runner taken as $6 \mathrm{~mm}$ ]

\section{STEP-4}

In this step standard sprue is selected by the designer and its diameter is adjusted according to the diameter of runner at one end and other diameter is derived from the relation,

$D 2=D 1+2 L \tan A$

Where,

D1= diameter of sprue at lower end

D2=diameter of sprue at upper end

$\mathrm{L}=$ length of sprue selected by the designer

$A=$ tapered angle $\left(2^{\circ}\right.$ to $\left.5^{\circ}\right)$

Hence sprue is selected with desired diameter, length and tapered angle.

\section{Moldflow analysis simulation}

Numerical simulation of polymer processing is getting more and more popular in the industry because it helps to forecast the problems that may occur due to the wrong tool design or unoptimized processing conditions. As result, a lot of money and time can be saved. The simulation is done before the final tool design phase, when the changes in tool design are still possible.

The simulation is usually done with special commercial programs, not only for injection moulding, but also for other processing technologies like extrusion, blow extrusion, calendaring, thermoforming, etc. The target of numerous research conducted with the use of numerical simulation of the injection moulding process is usually to obtain the pressure, temperature and shear rate distribution in a closed mould and investigation of melt flow front movement in cavity as well as determining the flow length in different injection moulding conditions.

It is possible to calculate the pressure required for total cavity filling, clamping force after cavity filling, evaluating the optimal processing conditions. The optimal processing conditions can be found during the filling, holding and cooling stage simulation. The criteria of optimization are the proper values of temperature, pressure, and shear rate and even their distribution in the moulded part (Rao and Ramni, 2013).

\section{Mold flow software}

Mold flow software has been developed by Mold flow International Pvt. Ltd., Australia. It helps in finite elemental analysis used in the design of plastic product, mould design and production of plastic components.

Following are the modules of MOLDFLOW software:

Flow Analysis: The Flow analysis is used to determine the gate position and filling pattern. It analyses polymer flow within the mould, optimizes mould cavity layout, balances runners and obtains mould processing conditions for filling \& packing phases of the Moulding cycle.

Cooling Analysis: It analyses the effect of cooling on flow, optimizes cooling line geometry \& processing conditions.

Process Optimization Analysis: It gives optimized- processing parameters for a component considering injection- moulding conditions.

Warpage Analysis: This analysis simulates the effect of Moulding on product geometry, isolates the dominant cause of warpage so that the correct remedy can be applied.

Shrinkage Analysis: This analysis gives dimensions of mould cavities, using shrinkage determined from specific grade material shrinkage data \& flow analysis results.

The analysis is carried out using the software Mold flow Plastic Adviser (Rao and Ramni, 2013). 


\section{The Benefits of Predictive Analysis are as below:}

To avoid the high costs and time delays associated with problems discovered at the start of manufacturing, it is necessary to consider the combined effects of part geometry, material selection, mold design and processing conditions on the manufacturability of a part. Using predictive analysis tools to simulate the injection molding process, organizations and industries can evaluate and optimize interactions among these variables during the design phases of a project before production begins, where the cost of change is minimal and the impact of the change is greatest.

Table 4 Input details for plastic adviser

\begin{tabular}{|c|c|}
\hline Material & Polypropylene copolymer \\
\hline Trade Name & APPCOM 8077 \\
\hline Mould Surface Temperature & $45^{\circ}$ \\
\hline Melt Temperature & $200^{\circ}$ \\
\hline Maximum Pressure & $35 \mathrm{MPa}$ \\
\hline Density & $950 \mathrm{~kg} / \mathrm{m}^{\wedge} 3$ \\
\hline
\end{tabular}

\section{Mold flow result}

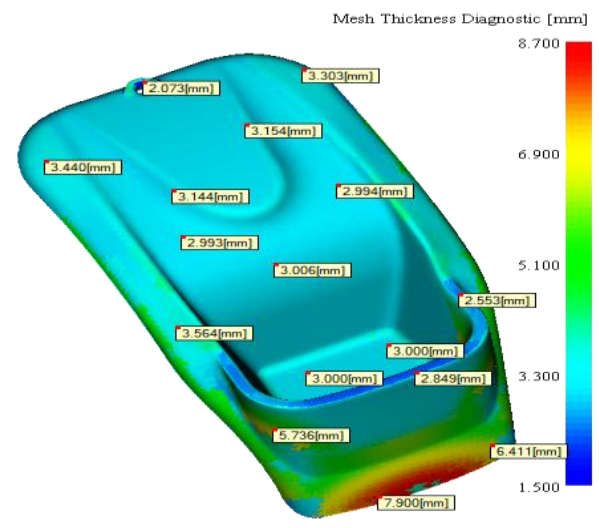

Fig. 2 Best gate location

The gate location result rates each place on the model for its suitability for an injection location. The most suitable areas, colored blue, are rated as best, and the least suitable areas of the model, colored red, are rated as worst.

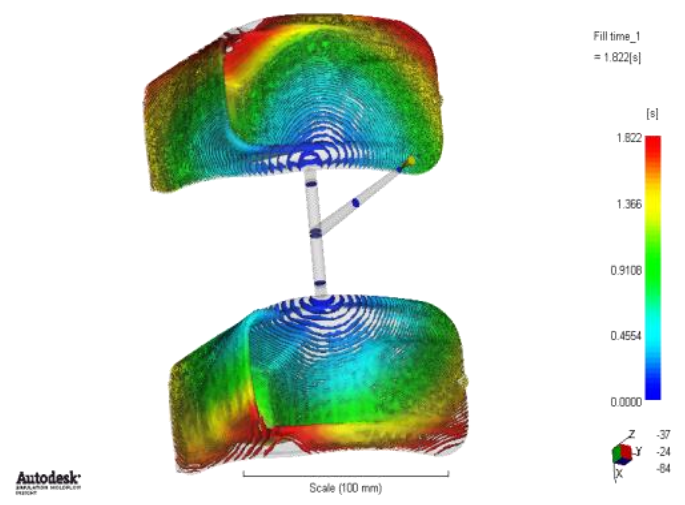

Fig. 3.Analysis for fill time
This result shows the flow path of the plastic through the part by plotting contours which join regions filling at the same time. These contours are displayed in a range of colors from red, to indicate the first region to fill, through to blue to indicate the last region to fill.

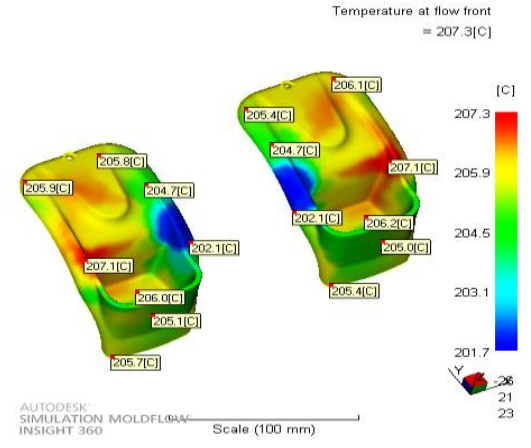

Fig. 4 Temperature at flow front

The flow front temperature result uses a range of colors to indicate the region of lowest temperature (colored blue) through to the region of highest temperature (colored red). The colors represent the material temperature at each point as that point was filled. The result shows the changes in the temperature of the flow front during filling.

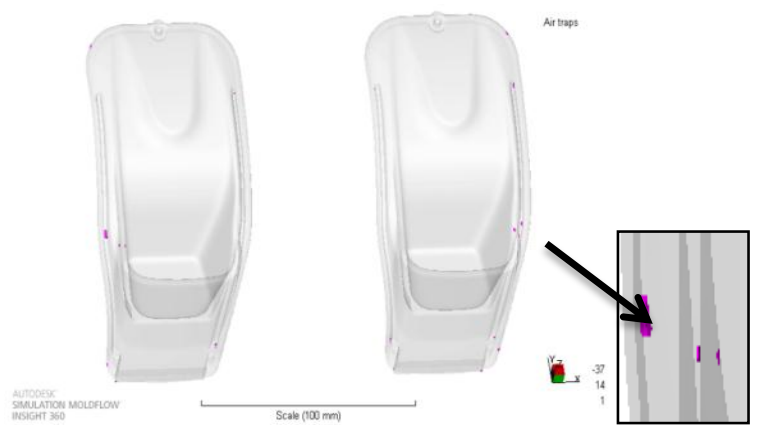

Fig. 5 Analysis for air traps

The air trap result shows the regions where the melt stops at a convergence of at least 2 flow fronts or at the last point of fill, where a bubble of air becomes trapped. The regions highlighted in the result are positions of possible air traps.
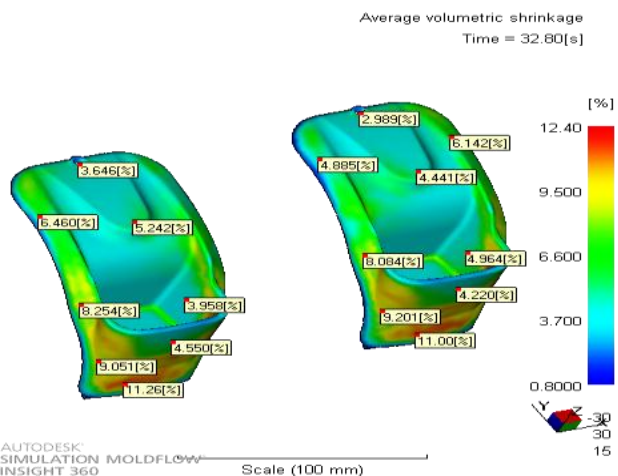

Fig. 6 Volumetric shrinkage at ejection 
As the hot plastic material cools in the mould, it contracts towards the centre, and will stick to core because of shrinkage factor. Thus, while designing a tool, the shrinkage allowance must be added to the core and cavity. Different materials will have different shrinkage

\section{Validation}

The design will be validated by producing the component without affecting the component's functionality. Flow of plastic will be observed. Dimensional accuracy will be measured and checked with the specified dimensions. Visual and actual inspection will be done while attempting to identify the defects. Further, the component will be checked for fitment in the sub-assembly

\section{Conclusion}

While designing a gating system, it is very important that the molten metal should fill the cavity properly.

1) A proper runner and a gating system is very important to secure good quality die through providing a homogeneous mould filling pattern.

2) Multi-cavity die will save labour cost and improve the production efficiency.

3) By increasing the gate thickness or area, the filling time and gate velocity varies accordingly. A large gate area will decrease both the filling time and gate velocity.

4) A low gate velocity will lead to high air entrapment and porosity. On the other hand low flow rate will result in poor casting surface. A short filling time gives good surface finish.

\section{References}

Jitendra Dilip Ganeshkar, Prof. R.B Patil, Swapnil S. Kulkarni, (2014) Design of 'plastic injection mold' for an automotive component through 'flow analysis' (CAE) for design enhancement, International Journal of Advanced Engineering Research and Studies E-ISSN2249-8974.

L.M. Galantucci, R. Spina, (2003) Evaluation of filling conditions of injection moulding by integrating numerical simulations and experimental tests, Journal of Materials Processing Technology 141, page no. 266-275.

Arjun Kapila, Kanwarjeet Singh, Gaurav Arora and Narayan Agarwal, (2015), Effect of Varying Gate Size on the Air Traps in Injection Molding,Vol.5, PageNo.161-166

Manish Patil, Bhavin Dave, Vijay Bhojani, Yogesh Kachrola, Vivek Bhut,( 2015) Design, Analysis and Optimum Selection of Mold Runner Section by using AHP (Analytical Hierarchy Process) method, International Journal of Advance Engineering and Research Development Volume 2,Issue 5

Jagannatha Rao M B, Dr. Ramni, (2013) Analysis of Plastic Flow in Two Plate Multi Cavity Injection Mould for Plastic Component for Pump Seal, International Journal of Scientific and Research Publications, Volume 3,Page no.1-3

Pankaj Shakkarwal and LipinYadav, (2013) Design and Mould Flow Analysis of Injection Mould for Connecting Link, International Journal on Emerging Technologies 4(1):Page no. 182-185.

Arvind Kumar Singh and D.K. Singh, (2012) Modelling and Analysis of Mould Filling Parameters for PP and ABS Materials Using Software Simulation, International Journal of Engineering Research \& Technology (IJERT)vol. 1, page no. $1-5$.

Dr. M P Singh, Akhilesh Jaguri,(2015) Gating System Design Optimization for Injection Moulding, International Journal of Mechanical and Industrial Technology, Vol. 3, Issue 1 page no.156-163

Ž. Rutkauskas, A. Bargelis,(2007) Knowledge - based method for gate and cold runner definition in injection mold design, page no. 49-53.

S. Kamaruddin, Zahid A. Khan and S. H. Foong,(2010) Application of Taguchi Method in the Optimization of Injection Moulding Parameters for Manufacturing Products from Plastic Blend, IACSIT International Journal of Engineering and Technology, Vol.2,page no. 574-580. 